Noëmi Manders-Huits and Michael Zimmer:

\title{
Values and Pragmatic Action: The Challenges of Introducing Ethical Intel- ligence in Technical Design Communities
}

\begin{abstract}
:
Various Value-Conscious Design frameworks have recently emerged to introduce moral and ethical intelligence into business and technical design contexts, with the goal of proactively influencing the design of technologies to account for moral and ethical values during the conception and design process. Two attempts to insert ethical intelligence into technical design communities to influence the design of technologies in ethical- and value-conscious ways are described, revealing discouraging results. Learning from these failed attempts, the article identifies three key challenges of pragmatic engagement with technical design communities: (1) confronting competing values; (2) identifying the role of the values advocate; and (3) the justification of a value framework. Addressing these challenges must become a priority if one is to be successful in pragmatically engaging with real-world business and design contexts to bring moral and ethical intelligence to bear in the design of emerging information and communication technologies.
\end{abstract}

\section{Agenda}

Implementing Value-Conscious Design: Successes and Disappointments

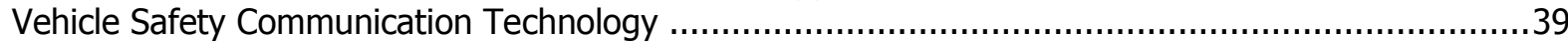

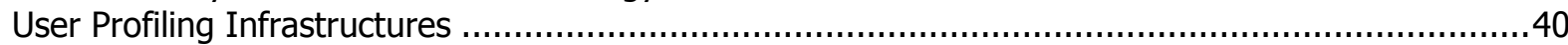

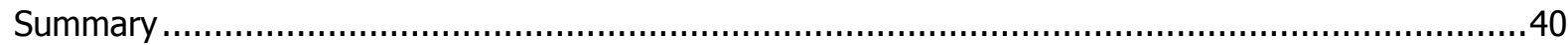

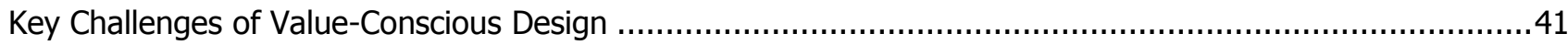

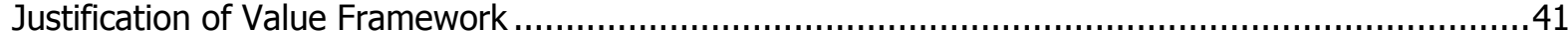

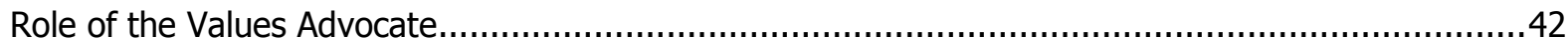

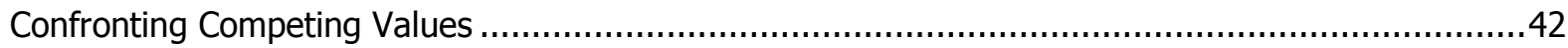

Conclusion.

\section{Author(s):}

Noëmi Manders-Huits:

- Organization and contact address: Philosophy Section, Delft University of Technology, PO Box 5015, 2600 GA Delft, The Netherlands

- Telephone, email and personal homepage: $:-31$ (0)15 $2781788, \square$ N.L.J.L.MandersHuits@tudelft.nl, 므 www.ethicsandtechnology.eu/index.php/persons/detail/83/

Michael Zimmer:

- Organization and contact address: School of Information Studies, University of Wisconsin-Milwaukee, 576 Bolton Hall, 3210 N. Maryland Ave, Milwaukee, WI 53211, USA

- . 
Advances in the power and ubiquity of information and communication technologies (ICT) has led to an explosion in new technological tools and services that have become the backbone of our contemporary information society. The inclusion of companies like Microsoft, Google, Apple, and Amazon in the S\&P 500 reveal the importance of ICT to our global economy. Success in this competitive business environment often comes to the ICT developer with the best business intelligence, most-skilled designers, and fastest deployment. Yet, the rapid speed of technological evolution and adoption often leaves little time for designers, managers, and other major stakeholders to anticipate and absorb the moral and ethical dimension of the ICTs they deploy. Lacking the time for lengthy reflection, technology companies are often forced to make hurried engineering and design choices that carry moral and ethical consequences.

While concern over the moral and ethical consequences of our modern technological era has existed for some time (see, for example, Friedman, 1997; Johnson \& Nissenbaum, 1995; Moor, 1985; Nissenbaum, 2001; Shrader-Frechette \& Westra, 1997), recent focus has been placed on how to develop pragmatic frameworks ensure that particular attention to moral and ethical values becomes an integral part of the conception, design, and development of ICT. These include innovative proposals such as Design for Values (Camp, n.d.), Values at Play (Flanagan, Howe, \& Nissenbaum, 2005; Flanagan, Howe, \& Nissenbaum, 2008), and Value Sensitive Design (Friedman, 1999; Friedman, Kahn, \& Borning, 2002). Each of these frameworks - which we will refer to collectively as Value-Conscious Design seek to broaden the criteria for judging the quality of technological systems to include the advancement of moral and human values, and to proactively influence the design of technologies to account for such values during the conception and design process. In other words, the goal of Value-Conscious Design is to bring moral and ethical intelligence into conversation with existing business and technical intelligence to inform and guide the design of emerging information and communication technologies.

We, the authors, have been involved in two separate attempts to engage with business and technical design communities to influence the design of emerging technological systems in ethical- and value-conscious ways. Unfortunately, the results were discouraging. Drawing from our interventions with business and technical design communities, this article will identify three key challenges of pragmatic engagement with technical design communities: (1) confronting competing values; (2) identifying the role of the values advocate; and (3) the justification of a value framework. Addressing these challenges must become a priority if one is to be successful in pragmatically engaging with real-world business and design contexts to bring moral and ethical intelligence to bear in the design of emerging information and communication technologies. ${ }^{103}$

\section{Implementing Value-Conscious Design: Successes and Disappointments}

The researchers who have championed the various Value-Conscious Design frameworks have enjoyed success in bringing moral and ethical intelligence to bear in the design of technologies, including the development of web browser cookie management tools in support of the values of informed consent and user privacy (Friedman, Howe, \& Felten, 2002), the embedding the value of trust in web browser tools to protect Internet users from consumer fraud and identity theft (Camp, 2006; Camp, Friedman, \& Genkina, n.d.), the construction of a computer game environment for teaching middle-school girls programming skills to help counter gender inequity in math and computer science while also embodying values such as cooperation, creativity, privacy and

${ }^{103}$ This article was inspired by the Values In Design Graduate Student Workshop held at Santa Clara University in August 2005. The authors would like to thank Geoffrey Bowker, Helen Nissenbaum, and the other workshop participants for stimulating the discussions that prompted the writing of this article. The authors also thank the faculty and students at the Department of Philosophy and the History of Technology at the Royal Institute of Technology, Stockholm, Sweden, the Center for Philosophy of Technology and Engineering Science at the University of Twente, Enschede, The Netherlands, the Philosophy Section at the Delft University of Technology, Delft, The Netherlands, as well as the attendees of the 2007 Computer Ethics: Philosophical Enquiry conference for their valuable feedback. Particular thanks to Helen Nissenbaum and Sabine Roeser for their thoughtful comments on earlier drafts of this article. This research was sponsored, in part, by an NSF Dissertation Grant (SES-0620772) and a travel grant provided by the Netherlands Organisation for Scientific Research (NWO, R 22-403). 
independence (Flanagan et al., 2005; Flanagan et al., 2008), and the creation of a web browser extension to help obfuscate one's web search history records to prevent profiling by search engine providers, fostering the values of privacy and user autonomy (Howe \& Nissenbaum, 2006). These cases reveal the promise of influencing the design of new information and communication technologies in order to account for moral and ethical values.

Encouraged by these successful implementations of the Value-Conscious Design framework, we, the authors, were optimistic as we engaged with the technical design communities of two emerging technological systems, aiming to introduce moral and ethical intelligence into their respective design spheres. Zimmer sought to ensure that the value of privacy became a constitutive part of the technological design of emerging networked vehicle safety communication (VSC) technologies in the United States, while Manders-Huits was part of a team of academics specializing in ethics of information technology who participated in a project to create a User Profiling Infrastructure in The Netherlands.

\section{Vehicle Safety Communication Technology}

Recent advances in wireless technologies have led to the development of intelligent, in-vehicle safety applications designed to share information about the actions of nearby vehicles, potential road hazards, and ultimately predict dangerous scenarios or imminent collisions. These vehicle safety communication (VSC) technologies rely on the creation of autonomous, self-organizing, wireless communication networks connecting vehicles with roadside infrastructure and with each other. In these networks, both vehicles and infrastructure collect local data from their immediate surroundings, process this information and exchange it with other networked vehicles to provide real-time safety information about the immediate surroundings. Data messages, which are automatically and continuously transmitted from the vehicle 10 times per second, potentially include the vehicle's location, time and date stamps, vehicle speed \& telemetry data, and a vehicle identifier. To help facilitate the development and implementation of VSC applications, seven major auto manufactures, in cooperation with the U.S. Department of Transportation, have formed a joint research program called the Vehicle Safety Communications Consortium (VSCC), with deployment of VSC technologies forecasted to occur between 2010 and 2016. ${ }^{104}$

Coupled with the predicted safety benefits of VSC applications, however, is a potential rise in the ability to surveil a driver engaging in her everyday activities on the roads and highways. VSC technologies potentially enable the collection of information on where drivers go, when they made their trips, and what routes they used. They represent a shift from drivers sharing only general and visuallyobservable information to the widespread and constant broadcasting of precise, digital information about their daily activities (Zimmer, 2005). The potential integration of VSC technologies into our daily activities on the public roads threatens to foster a scenario where we might be "driving into the panopticon" (Reiman, 1995) of widespread surveillance, and the potential erosion of the values of privacy and autonomy as we drive along the roads.

Since VSC technologies and their related technical protocols and communication standards are still in the developmental stage, Zimmer, with support from the PORTIA project, ${ }^{105}$ took the opportunity to apply Value-Conscious Design principles in an attempt to influence the design of VSC technologies so that the value of privacy would become a constitutive part of the design process. Zimmer interacted with VSC project managers and engineers, was given access to technical white papers, and distributed his findings regarding the potential privacy and surveillance threats of VSC technologies. Unfortunately, the results of his engagement with the VSC design community were discouraging. Zimmer's efforts were met with skepticism: some designers viewed that the security gained through data encryption as a sufficient means of protecting user privacy, while others disregarded the threat to privacy altogether. Some potential privacyprotecting encryption solutions (see, for example, Boneh, Boyen, \& Shacham, 2004) were rejected, apparently due to concerns over efficiency and costs

104 For more information see U.S. Department of Transportation (2005), and Vehicle Safety Communications Consortium.

105 The PORTIA project is a five-year, multiinstitutional, multi-disciplinary, multi-modal investigation funded by the National Science Foundation in the Information Technology Research (ITR) program. For more information, see http://crypto.stanford.edu/portia/. 
outweighing the privacy protections gained. Opportunities to engage further with the design community to address user privacy were hindered, as scheduled "privacy workshops" were cancelled by working groups, while changing personnel and legal concerns stymied sustained collaboration with more sympathetic designers.

In total, while the introduction of new moral and ethical intelligence into the design sphere for VSC technologies brought some increased awareness of the related privacy concerns, full and direct engagement with this design community to achieve the Value-Conscious Design of these emerging technologies remained limited.

\section{User Profiling Infrastructures}

Online organizations are increasingly collecting data on users browsing and purchasing habits in order to create detailed user profiles, providing the tools to predict user behavior and provide personalized products and services. For example, online bookstores track and collect information about users' browsing and purchase history on their sites, resulting in the creation of detailed user profiles which allow the site to provide personalized purchase recommendations. Alongside this growing reliance on user profiles is the desire to be able to build, share and transfer profiles across various systems and platforms - the creation of a widespread User Profiling Infrastructure. For example, the user profile created on the online bookstore could also be shared with a different organization, like a movie rental company, to help predict what kind of movies the customer might want to watch. Similarly, a third party might be able to use a user Profiling Infrastructure to collect information on users' actions across various systems, such as a law enforcement agency monitoring purchasing habits across various websites in order to predict illegal activity.

While potentially useful, the cross-domain user profiling enabled by a User Profiling Infrastructure is fraught with value and ethical considerations, such as trust, informed consent, privacy and control over the flow of one's personal information. Recognizing the importance of addressing these value and ethical concerns, a team of academics specializing in ethics of information technology was invited to join the technical design team to help inform the development of such an architecture. As part of this team, Manders-Huits participated in design meetings and discussions, did research in relevant ethical under consideration protect user privacy and other ethical concerns. ${ }^{106}$ Overall, there was a concerted effort to introduce moral and ethical intelligence into the business and technical design environment in order to engage in the Value-Conscious Design of this emerging technical system.

This effort turned out to be more challenging than expected. While the technical designers were confronted with the challenges of the novel research field of ethics and technology, the ethicists found it equally challenging to apply ethical principles to the novelty and uncertainty of a still-emerging technical infrastructure. It was especially difficult to properly explicate and translate ethical considerations to workable requirements and specifications for the other project participants actually building the system. In other words, it proved difficult to operationalize the values so they could be put into the technical design. More discouraging, however, was the insertion of a new project management team who didn't share the same commitment to valueconscious design or an appreciation for the demands such efforts bring to the design process. When it came time to speed up the progress of the overall project, eliminating (what were perceived as) the complex and time-consuming ethical concerns seemed the easiest route to get the project back on schedule. As a result, the introduction of moral and ethical intelligence was ultimately rejected.

\section{Summary}

While some of the original framers of the ValueConscious Design (VCD) frameworks have enjoyed success in designing technologies that sustain moral and ethical values, the attempts by Manders-Huits and Zimmer were disappointing and failed to achieve the desired results. One key difference between the successful introduction of moral and ethical intelligence into business and technical design contexts by the original framers of VCD, and the less-successful efforts by the authors, is the particular sites of engagement. The successful applications of Value-Conscious Design principles noted above share a common characteristic of being situated in the relatively non-hostile design environment of the academic laboratory. Each project's design team was, by and large, comprised entirely of academics committed to the goal of achieving

\section{For more information https://doc.telin.nl/dscgi/ds.py/Get/File- 52040/TUD sotas.pdf} literature, and identified critical points for intervention to ensure that the User Profiling Infrastructure

see

Noëmi Manders-Huits and Michael Zimmer:

Values and Pragmatic Action: The Challenges of Introducing Ethical Intelligence in Technical Design Communities 
Value-Conscious Design, creating a design context quite welcoming of each projects' goals.

In contrast, Manders-Huits and Zimmer attempted to take the principles of Value-Conscious Design outside the laboratory and engage directly with designers of emerging technical systems in their native environments, revealing unique challenges that must be addressed in order to successfully introduce moral and ethical intelligence into "realworld" business and technical design environments outside the walls of academia.

\section{Key Challenges of Value- Conscious Design}

The unsatisfactory attempts to engage in ValueConscious Design detailed above illuminate three key challenges that must be addressed before these pragmatic frameworks can be fully and successfully deployed in design contexts outside the academic laboratory: (1) the justification of a value framework, (2) identifying the role of a values advocate, and (3) confronting competing values. Attention to each of these challenges is critical to ensure moral and ethical intelligence can enter into business and technical design environments.

\section{Justification of Value Framework}

It is important to identify whose moral framework we are considering in each specific design setting. The challenge is to identify the extent or limits of the design community: Is it composed only of the actual technology designers, e.g. the engineers, or including contractors, managers, companies, potential customers, etc.? In other words, 'whose' moral framework are we to study? After the identification of the design community and their values - as far as these are tangible - an important step can be taken with respect to value choices in the design process.

The aim of the specific value conscious design project also needs to be framed in terms of the normative stance one wishes to take. One might prefer an 'organic, emergent' moral framework to justify the value choices to be encountered, or have a more specific and predetermined moral framework in mind, driven by a specific normative outlook. Either way the starting point for moral evaluation needs to be clarified so that it is clear what is to be expected with regard to the value commitments of the technology. Accordingly, the design process of the particular technology can be structured accord- ing to certain points of intervention with respect to value choices.

Friedman and her collaborators (Friedman et al., 2002) argue with respect to universal and particular values that a value sensitive design should be flexible with respect to local values. A practical illustration of this is provided by the RAPUNSEL project (Flanagan et al., 2005). In this computer gaming design, players are tempted to take on part of the design of the game by choosing any particular set of preferences or normative outlook before entering into the game. A potential participant finds herself forced to choose between certain physical attributes, gender, race, etc. before entering the game. As she may not be comfortable with regard to any of these pre-designed categories, the designers allow significant flexibility to add nuances to the character. This flexible design feature, however, is easily provided from the safe settings of the academic gaming environment and we wonder, referring back, if this flexibility is equally manageable outside of these settings. Economic interests might constrain the number of options made available in a commercial gaming environment, and any such limitations present artificially simplify the complexity of moral life.

The justification of (pre-)determined value choices during design demands clarification of the moral framework being used with respect to freedom from bias, autonomy, privacy, equity and other human values. Moreover, it calls for a different way of doing ethics. Where traditionally, ethics is a field where past events are discussed and evaluated in order to develop a comprehensive account of moral choices and phenomena, what is required for a successful implementation of moral theory and values into design, is the "frontloading of ethics" (Van Den Hoven, 2005), also referred to as the changing of a retroactive to a proactive application of ethics. This is a challenging enterprise. Since technology design cases are fundamentally uncertain and with complex future outcomes, it is difficult from an ethical perspective to provide a useful account for dealing with value choices. It demands a revolution in ethics where traditional accounts are reconsidered in light of the complexity of technological design. An important first step in the frontloading of ethics is establishing the role of a values advocate on technical design teams. However, as the next section will detail, this is often a complicated and contentious task. 


\section{Role of the Values Advocate}

It is the challenge for the values advocate to support all value choices with the necessary normative justification. The acceptance of the values advocate in the design team as holder of particular expertise is dependent on the perception that the value choices and positions held by the advocate are rationally and theoretically justified. We think all choices in the design process have moral import. It is the task of the values advocate to make these as explicit as possible. In some cases the values advocate may also need to justify his or her own presence in the design team, and why designers, or anyone for that matter, should be concerned with values of moral import in the first place.

Further, we envision an array of roles that the values advocate can take within a particular design context: the authoritarian role, the supporting role or the leadership role. In the first role, the values advocate is regarded as authoritative in the ethical and value considerations at hand, implementing value-conscious decisions using a top-down strategy. Such a role is often confrontational, where pressure is exerted (both internally and externally) to ensure proper attention to values. A second role, the supporting role, is a comparately passive accompaniment of the design process, raising awareness at moments where value choices are being made and pointing to possible alternatives without advocating the one or the other. An advocate in this role is often merely advisory, and might have little more than token input on design decisions. Finally, the leadership role enables the values advocate to be both supporting but also directing when it comes to value choices. By providing insight to the complexity and delicacy of value choices basing on theoretical knowledge as well as acquired practical expertise, the values advocate in her role as leader is able to educate the other members of the design team (and possibly other stakeholders) and to strongly promote certain choices over others where necessary. We argue the leadership role to be the preferred positioning of the values advocate within a design team, taking into account shared responsibility for value choices (whereas the first example of an authoritative role might be too heavy-handed) and a proactive stance of the values advocate (whereas the example of a supporting role might be too passive).

\section{Confronting Competing Values}

Perhaps the most apparent challenge of engaging in Value-Conscious Design outside the academic labor- atory is the inevitability of confronting competing values within varied design contexts. Rather than benefiting from working within the academic sphere committed to the primacy of designing for moral values, design contexts outside academia often include stakeholders whose goals might come into conflict with the protection of these values.

For example, Howe and Nissenbaum's TrackMeNot web browser extension was developed using Mozilla's open-source browser application framework and posted to a website for download by the user and development community. As an academic project, little concern was necessary for production or distribution costs, advertising, profits, or other factors typically in play in commercial software development contexts. In contrast, the attempts at pragmatic engagement in design contexts outside academia by Manders-Huits and Zimmer exposed how the pressures of the marketplace - with its focus on instrumental values of efficiency, productivity and profitability - might result in hostility to the privileging of moral values in the design process. As Agre and Harbs (1994) warn, standard-setting processes often "embed a wide variety of political agendas" and the process of developing those standards will be "contested along a variety of fronts by various parties" (p. 84). The same can be said for technical design overall, and engaging in Value-Conscious Design in real-world design contexts will require the ability to negotiate such instances of conflicting values. ${ }^{107}$

We claim that, for a fully engaged and pragmatic application of Value Conscious Design to be successful, it must ensure that values are not only discovered and clarified, but also consciously and deliberately built into design, even if such embedding of values conflicts with other design objectives. This questions the supremacy of some values over others (hierarchy of values) and the way value choices in design are dealt with in light of supporting value systems or political/ethical convictions. While some embrace a more cultural constructivist approach where values are taken as perceived by the majority of the people, we take a more normative position. Here, ethics provides (other) grounds for identifying values and arguing for the enclosure or the supre-

107 To their credit, Flanagan and her colleagues make it clear in their discussion of the RAPUNSEL project that such projects, when pursued purely within academic contexts, fail to "address all factors that, for example, a commercial project would be obliged to address" (Flanagan et al., 2008). 
macy of certain values over others, possibly against the (uncritical) majority opinion. We argue that, for morality to be designed into technical systems and institutions, value choices should be based on wellconsidered ethical judgments, coherent with our attitude towards how we think the world is best served and structured from a moral perspective. This involves a critical attitude towards certain aims of research and design that are often taken for granted, such as maximum efficiency, maximum profitability, and so on.

\section{Conclusion}

We have identified three key challenges that must be addressed if scholars committed to ValueConscious Design are to be successful in pragmatically engaging within business and technical design communities to introduce moral and ethical intelligence into the decision-making matrix. First, we confront the broad philosophical challenge of providing a sufficient justification of the value and moral framework we embrace when engaging in valueconscious design. Second, the role of the values advocate must be both clearly defined and justified to fulfill its role as an essential component of technical design teams. Finally, we must find strategies to successfully resolve the inevitable value conflicts when engaging with design communities outside of academia.

Our goal with this article is not to discredit the accomplishments of the existing Value-Conscious Design efforts, but merely to show that pragmatic challenges remain. Moreover, like many academic probes, this article presents more questions than answers. By bringing focus to these challenges, however, we hope to spark new critical reflection within the Value-Conscious Design community (within which we include ourselves) of how to best engage with real-world design communities to introduce moral and ethical intelligence into business and design contexts. Addressing these challenges will increase the chances for success of future pragmatic engagements with design communities to proactively influence the design of emerging technologies to take account of ethical and human values.

\section{References}

Agre, P. \& Harbs, C. (1994). Social Choice about Privacy: Intelligent Vehicle-highway Systems in the United States. Information Technology and People, 7(4), 63-90.
Boneh, D., Boyen, X., \& Shacham, H. (2004). Short group signatures. Proceedings of Crypto, 4, 4155.

Camp, L. J. (2006). Reliable, Usable Signaling to Defeat Masquerade Attacks. Retrieved September 23, 2006, from http://www.ljean.com/files/NetTrustEcon.pdf

Camp, L. J. (n.d.). Design for Values, Design for Trust. Retrieved September 20, 2006, from http://www.ljean.com/design.html

Camp, L. J., Friedman, A., \& Genkina, A. (n.d.). Embedding Trust via Social Context in Virtual Spaces. Retrieved September 23, 2006, from http://www.ljean.com/files/NetTrust.pdf

Flanagan, M., Howe, D., \& Nissenbaum, H. (2005). Values at play: Design tradeoffs in socially oriented game design. Conference on Human Factors in Computing Systems, 751-760.

Flanagan, M., Howe, D., \& Nissenbaum, H. (2008). Values in Design: Theory and Practice. In J. van den Hoven \& J. Weckert (Eds.), Information Technology and Moral Philosophy. Cambridge University Press.

Friedman, B. (1997). Human values and the design of computer technology (CSLI lecture notes. ; no. 72). New York: Cambridge University Press.

Friedman, B. (1999). Value-Sensitive Design: A Research Agenda for Information Technology. National Science Foundation, Contract No: SBR9729633).

Friedman, B., Howe, D., \& Felten, E. (2002). Informed consent in the Mozilla browser: Implementing value-sensitive design. Proceedings of the 35th Annual Hawaii International Conference on System Sciences.

Friedman, B., Kahn, P., \& Borning, A. (2002). Value Sensitive Design: Theory and Methods. (Technical Report 02-12-01).

Howe, D. \& Nissenbaum, H. (2006). TrackMeNot. Retrieved August 27, 2006, from http://mrl.nyu.edu/ dhowe/TrackMeNot

Johnson, D. \& Nissenbaum, H. (Eds.). (1995). Computers, ethics \& social values. Englewood Cliffs, N.J: Prentice Hall.

Moor, J. (1985). What is computer ethics? Metaphilosophy, 16, 266-275.

Nissenbaum, H. (2001). How computer systems embody values. IEEE Computer, 34(3), 118-120.

Reiman, J. (1995). Driving to the panopticon: $A$ philosophical exploration of the risks to privacy posed by the highway technology of the future. 
Santa Clara Computer and High Technology Law Journal, 11(1), 27-44.

Shrader-Frechette, K. \& Westra, L. (Eds.). (1997). Technology and values. Lanham, MD: Rowman \& Littlefield.

U.S. Department of Transportation. (2005). Vehicle Infrastructure Integration (VII): Major initiatives. Retrieved December 18, 2005, from http://www.its.dot.gov/vii/vii_overview.htm

Van Den Hoven, M. J. (2005). Design For Values And Values For Design. Information Age, $\mathrm{Au}-$ gust/September, 4-7.

Vehicle Safety Communications Consortium. (n.d.). Vehicle safety communications project: Task 3 final report: identify intelligent vehicle safety applications enabled by DSRC. (on file with author)

Zimmer, M. (2005). Surveillance, privacy and the ethics of vehicle safety communication technologies. Ethics and Information Technology, 7(4), 201-210. 